\title{
O TEATRO COMO FERRAMENTA DE PROMOÇÃO DE EDUCAÇÃO AMBIENTAL
}

Thierry Betazzi Lummertz ${ }^{1}$

Marta Luciane Fischer ${ }^{2}$

Resumo: A efetividade das intervenções de Educação Ambiental (EA) depende do uso correto de ferramentas de comunicação devidamente inseridas no contexto pedagógico. Assim, questionou-se como tem sido empregado o teatro na EA, objetivando quantificar as ferramentas utilizadas na EA em conteúdos científicos e populares e, caracterizar o emprego do teatro em práticas educativas por meio de entrevistas com educadores ambientais e atores. Os resultados evidenciaram que as ações da EA estão direcionadas a novas práticas e focadas no público infantil, devendo o teatro ser planejado de forma estruturada de acordo com o público alvo, utilizando linguagens apropriadas e envolvendo educadores ambientais e atores.

Palavras-chave: Arte e Educação; Educadores Ambientais; Bioética Ambiental; Metodologias Ativas de Ensino-Aprendizagem.

${ }^{1}$ Pontifícia Universidade Católica do Paraná. E-mail: thierryl.ator@gmail.com

2 Pontifícia Universidade Católica do Paraná - PPGB. E-mail: marta.fischer@pucpr.br 


\section{Introdução}

O desenvolvimento da consciência ambiental, por meio de intervenções de Educação Ambiental (EA), acentuou-se nas duas últimas décadas como consequência dos acordos tratados em conferências mundiais (SATO, 2003). A EA objetiva desenvolver habilidades e modificar as atitudes em relação ao ambiente, que, por meio da compreensão e apreciação das inter-relações entre os seres, visa à formação de sujeitos conscientes, críticos, politizados, autônomos e protagonistas nas tomadas de decisões individuais e coletivas (LOUREIRO, 2009; MULLER; FARIA, 2005; LAYRARGUES, 2004; SATO, 2003). A EA surgiu concomitantemente à Ética Ambiental instauradora dos debates sobre a conduta dos seres humanos com os demais seres vivos, desta e de gerações futuras, conclamando por uma ferramenta de conscientização e transformação (FISCHER et al. 2017a). Fischer et al. (2017) justificaram a consolidação da Bioética Ambiental em detrimento da Ética Ambiental, ao identificarem nesta um campo disciplinar de base filosófica. Logo, inábil em atender as demandas de uma ferramenta para EA que promova a intermediação de questões complexas, plurais e globais, por meio do diálogo, da identificação e da mitigação de vulnerabilidades em um contexto multidisciplinar, como se propõe a Bioética Ambiental.

A Bioética Ambiental visa a reflexão de diferentes segmentos sociais a respeito de questões éticas urgentes por meio do diálogo entre os interesses pessoais e econômicos da comunidade com os interesses conservacionistas. A intervenção deve ocorrer através da EA, contudo, a transposição das reflexões teóricas e o elo entre a academia e a sociedade demanda um processo crítico, consciente e estruturado, considerando as diferentes linguagens, percepções, interesses, experiências, idades, sexos/gêneros, hábitos alimentares e locais de moradia para que desta forma sejam promovidas as adequações das estratégias teórico-metodológicas (FISCHER; MOLINARI, 2016). Segundo Fischer e Molinari (2016) os programas de EA devem se beneficiar do fato da geração atual ter se desenvolvido em meio a debates ambientais e ativistas absolutistas e, consequentemente, alicerçadas em princípios universais e empáticos às questões ambientais. A Bioética Ambiental não se propõe a solucionar problemas ecológicos, mas sim implementar uma ferramenta que dialoga, levanta pontos de reflexão e permite uma coparticipação na construção de valores e intervenções para contenção desses problemas. Logo, a EA deve conduzir o cidadão ao protagonismo no exercício do direito ao meio ambiente ecologicamente equilibrado, para o uso comum, melhorando a qualidade de vida de todos os seres-vivos. Para isso, a EA deve se apropriar dos temas debatidos na Bioética Ambiental e estar engajada em todos os níveis de escolaridade, para fortalecer a conscientização do sujeito para preservação do ambiente e para a compreensão do seu papel como cidadão. Sendo assim, a EA não deve se limitar à educação formal, estendendo seu espectro de atuação em ações conjuntas voltadas à sensibilização da coletividade sobre questões ambientais, e à sua organização e participação na defesa da qualidade do ambiente (FISCHER; MOLINARI, 2016).

revista brasileira educação ambiental 
O teatro é tradicionalmente e amplamente utilizado como ferramenta da EA, balizado em suas propriedades de comunicação e por meio de linguagem não verbal associada à verbal, estimulando simultaneamente o lúdico e a reflexão, facilitando a compreensão do mundo ao seu redor (SATO, 2003). Segundo Araújo e Pasquarelli-Filho (2013), o teatro pedagógico tem grande potencial para a EA em uma perspectiva emancipatória e complexa.

O teatro surgiu como uma forma de ritualização, utilizada por povos primitivos na adoração dos deuses, sendo sua origem oficial vinculada à Era Clássica, na Grécia. Com a dominação da Grécia pelo Império Romano, a arte do teatro foi absorvida e deturpada para o mote político de oferecimento de "pão e circo" para sociedade (BERTHOLD, 2005). Durante a Idade Média, o teatro perdeu consideravelmente sua conotação política, apesar da íntima relação entre ambos, inserindo-o no contexto de manifestações religiosas. Nos séculos seguintes, o teatro criou consciência nacional, permitindo novas reflexões e ideias, sendo seu foco a natureza e sua relação com o homem (FRANK, 1954; BERTHOLD, 2005). Ao longo dos anos, passou a ser influenciado pelo capitalismo, tornando-se popular nos EUA, sendo até hoje utilizado principalmente com o intuito comercial (BERTHOLD, 2005).

Embora o teatro tenha surgido com a finalidade cultural, ao longo do tempo sofreu transformações determinadas pelas necessidades sociais. A concretização da EA em todos os níveis de escolaridade, na amplitude formal e não formal, deparou-se com a necessidade de adaptar as intervenções ao público-alvo, a fim de alcançar a efetividade de transformadores da realidade e promotores da participação política, demandando de ferramentas de comunicação eficazes. O teatro é coadjuvante no processo de aprendizagem e desenvolvimento humano, assim como na alfabetização ecológica, firmando-se na sua efetiva forma de comunicação e influência nas transformações sociais (BOAL, 1998). Dessa forma, o teatro instiga uma participação mais efetiva dos educandos sobre os temas em discussão, tornando-os atores dentro dos limites do palco e transformando suas percepções e seus sentidos em relação à vida, contribuindo para mudar sua consciência e suas atitudes no mundo real (ARAÚJO; PASQUARELLI-JUNIOR, 2006; THIOLLENT, 1988). A profissão de ator é reconhecida desde 1978 pela lei 6533 e decreto 82385 (SATEDSP, 2010).

A relevância do presente estudo reside no fato de que além da EA ser uma necessidade para a conscientização socioambiental (SATO, 2003), o teatro é uma ferramenta frequentemente utilizada nessa prática (ARAÚJO; PASQUARELLI-JUNIOR, 2006), todavia de forma intuitiva sem uma preocupação maior dos educadores de diferentes áreas em compreender os processos de comunicação inerentes ao teatro. A ideia central desenvolvida no presente estudo foi a compreensão do teatro como uma importante ferramenta de subsídio para a orientação de profissionais na aplicação das ações da EA, principalmente devido a maioria dos profissionais que usam a ferramenta necessariamente não terem uma formação na área de educação ou teatro. Logo, questionou-se se a utilização e o grau de importância atribuído ao teatro 
no processo de EA, e qual seria a melhor forma de aplicação e avaliação. A hipótese do presente estudo foi que embora amplamente utilizada como meio de promover motivação para a EA, a aplicação de forma desestruturada pode resultar na dificuldade de avaliação dos resultados das intervenções. Sendo assim, o objetivo desta investigação foi avaliar a utilização do teatro como ferramenta da EA, bem como a sua implementação em diversas situações, estabelecendo, por meio dos educadores ambientais, sua eficácia na influência de mudança de comportamento para formar indivíduos conscientemente críticos e ativos nas tomadas de decisões socioambientais.

\section{Material e métodos}

A presente pesquisa consistiu em um estudo quantitativo composto por análise de conteúdo científico e popular.

\section{Análise do conteúdo científico e popular}

A categorização e análise de relatos de intervenções que utilizaram a EA no meio científico se deram por meio da recuperação de documentos veiculados em revistas científicas, teses, dissertações e trabalhos apresentados em congressos. Para recuperar os textos foi utilizada a ferramenta Google Acadêmico, na qual foram empregados os descritores "Educação Ambiental" e "Educação Ambiental e teatro". Os textos científicos recuperados foram selecionados, incialmente, constando a ocorrência do termo Educação Ambiental e, posteriormente, teatro, selecionando apenas aqueles escopos do presente estudo.

Para a recuperação de conteúdo popular digital, foi utilizada a ferramenta Google.com, devido à sua popularidade no Brasil, destituída de login, aplicando os mesmos unitermos listados acima. O conteúdo recuperado foi relativo aos 100 primeiros registros.

Os conteúdos científicos e populares foram categorizados segundo a técnica de Bardin (2011) de acordo com o público-alvo, o objetivo, a metodologia utilizada, a forma de avaliação e os resultados obtidos. A homogeneidade da representatividade das categorias dos parâmetros avaliativos utilizados na análise do conteúdo digital e popular foi inferida por meio da aplicação do teste de aderência denominado Goodness of fit (GTest). Esse teste avalia, com maior sensibilidade e acurácia, se foi ao acaso, logo em igual proporção, as frequências das categorias de uma determinada variável, ou se determinadas categorias foram significativamente mais frequentes. Para tal, foi considerada a significância de $95 \%$, ou seja, para o resultado do teste ser aceito como verdadeiro, admitiu-se uma probabilidade de erro menor do que $5 \%(P<0,05)$. 


\section{Entrevista com profissionais}

A concepção dos profissionais foi obtida por meio de 20 entrevistas, sendo 10 para profissionais que atuavam como educadores ambientais e que utilizavam ou não o teatro como ferramenta da $E A$, e 10 para profissionais do teatro. $O$ instrumento especialmente construído para essa pesquisa constou de uma entrevista semiestruturada, sendo questionado para os educadores ambientais: a) os trabalhos realizados, focando nos temas e públicos; b) as dificuldades e satisfações vividas nas práticas de Educação Ambiental; c) os métodos utilizados e os mais eficientes; d) a relação entre o público-alvo e o método; e) a importância do teatro, e se o profissional já teve contato com o mesmo, se considera um bom método; f) como se avalia os resultados de suas intervenções. Para os 10 atores entrevistados questionou-se: a) a relação entre teatro e educação, se esses profissionais já haviam participado de ações envolvendo teatro e educação, bem como se o teatro é uma boa ferramenta nessas ações; b) os pré-requisitos para a utilização do teatro, se deve diferenciar a aplicação do teatro de acordo com o público e qual a melhor forma de potencializar a aprendizagem, atuando ou assistindo um espetáculo; c) como avaliavam os resultados das mudanças de comportamento. As entrevistas foram analisadas qualitativamente.

Para atender aos princípios éticos o estudo foi realizado em conformidade com a declaração Helsinque e Resoluções CNS n. 466/12 e n. 510/2016, respeitando a integridade e o anonimato dos entrevistados, bem como 0 tratamento, a análise e a preservação dos dados. O projeto detém aprovação do CEP/PUCPR n. 5961. Foi explicado ao participante a importância do estudo, o foco e os questionamentos, seguidos do preenchimento do Termo Livre de Consentimento Esclarecido, arquivado no Laboratório Núcleo de Estudos do

Comportamento Animal NEC-PUCPR. Foi assegurado também o sigilo dos participantes.

\section{Resultados}

\section{Análise do conteúdo científico e popular}

Nos conteúdos analisados predominaram a associação da EA com temas relacionados com as tecnologias metodológicas (Gtest(4)=143; $\mathrm{P}<0,0001$ ), associados com 30 temas específicos, sendo cinco específicos dos conteúdos científicos, nove dos populares e cinco em comum. Dentre aqueles que foram usados em mais de cinco conteúdos, houve maior frequência da "interação com o ambiente" ( $G_{\text {test }(7)=-6,1 ; P<0,0001)}$ no total e em ambas abordagens e da água no conteúdo popular $\left(G_{\text {test }}(7)=19 ; P<0,0001\right)$ (Tabela 1). Os demais temas identificados foram; agrotóxicos, alimentos, árvores frutíferas, caça, capacitação, cidadania, critérios de avaliação, drogas, DST, EA no trabalho, energia, florestas, fogo, internet, saúde, pré-história, reflorestamento, respeito ao próximo, respeito aos animais, segurança no trabalho e solos. Os textos científicos foram direcionados principalmente para intervenções com

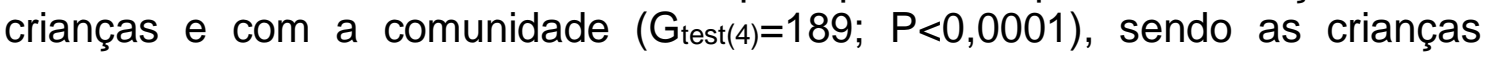
Revbea, São Paulo, V. 12, № 5: 56-72, 2017. 


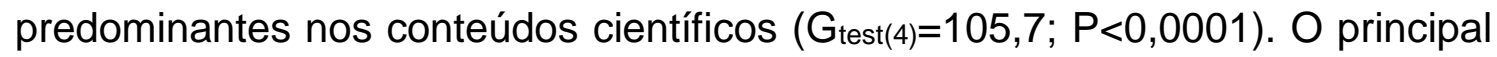
objetivo das intervenções analisadas foi a conscientização $\left(G_{\text {test }(3)=-205 \text {; }}\right.$ $\mathrm{P}<0,0001)$ (Tabela 1).

Tabela 1: Categorização dos textos científicos e populares sobre a intervenção de Educação Ambiental.

\begin{tabular}{|c|c|c|c|c|}
\hline Parâmetro & Categorias & $\begin{array}{l}\text { Científico } \\
(N=105)\end{array}$ & $\begin{array}{l}\text { Popular } \\
(N=100)\end{array}$ & Total \\
\hline Tema geral & $\begin{array}{l}\text { Tecnologias metodológicas } \\
\text { Áreas naturais } \\
\text { Áreas urbanas } \\
\text { Outros } \\
\text { Área agrícola }\end{array}$ & $\begin{array}{l}38,1 \%\left(^{*}\right) \\
28,6 \%\left(^{*}\right) \\
15 \% \\
19 \% \\
1 \%\end{array}$ & $\begin{array}{l}34 \%\left(^{*}\right) \\
44 \%\left(^{*}\right) \\
2 \% \\
6 \% \\
12 \%\end{array}$ & $\begin{array}{l}36,1 \%\left(^{*}\right) \\
36,1 \%\left(^{*}\right) \\
8,3 \% \\
12,2 \% \\
12,5 \%\end{array}$ \\
\hline $\begin{array}{l}\text { Temas } \\
\text { específicos } \\
(\mathrm{N} \geq 5)\end{array}$ & $\begin{array}{l}\text { Água } \\
\text { Biodiversidade } \\
\text { Institucionalizar a EA } \\
\text { Interação com Ambiente } \\
\text { Interdisciplinaridade } \\
\text { Lixo } \\
\text { Poluição e degradação ambiental } \\
\text { Sustentabilidade }\end{array}$ & $\begin{array}{l}8 \% \\
4 \% \\
8 \% \\
60 \%\left({ }^{*}\right) \\
6 \% \\
11 \% \\
- \\
3 \%\end{array}$ & $\begin{array}{l}24,2 \%\left(^{*}\right) \\
11 \% \\
1,1 \% \\
20,9 \%\left({ }^{*}\right) \\
- \\
11 \% \\
17,6 \% \\
14,3 \%\end{array}$ & $\begin{array}{l}15,7 \%\left(^{*}\right) \\
7,3 \% \\
4,7 \% \\
41,4 \%\left(^{*}\right) \\
3,1 \% \\
11 \% \\
8,4 \% \\
8,4 \%\end{array}$ \\
\hline Público & $\begin{array}{l}\text { Comunidade } \\
\text { Crianças } \\
\text { Idosos } \\
\text { Jovens } \\
\text { Professores }\end{array}$ & $\begin{array}{l}26,9 \% \\
51 \%\left(^{*}\right) \\
1,9 \% \\
9,6 \% \\
10,6 \%\end{array}$ & $\begin{array}{l}42 \%\left(^{\star}\right) \\
39 \%\left({ }^{*}\right) \\
- \\
4 \% \\
14 \%\end{array}$ & $\begin{array}{l}34,5 \%\left({ }^{*}\right) \\
45,3 \%\left({ }^{*}\right) \\
1 \% \\
6,9 \% \\
12,3 \%\end{array}$ \\
\hline Objetivo & $\begin{array}{l}\text { Capacitar } \\
\text { Conscientizar } \\
\text { Diagnosticar } \\
\text { Ferramenta de informação }\end{array}$ & $\begin{array}{l}3,8 \% \\
65,7 \%\left(^{\star}\right) \\
8,6 \% \\
21,9 \%\end{array}$ & $\begin{array}{l}20,8 \% \\
73,6 \%\left(^{\star}\right) \\
2,8 \% \\
2,8 \%\end{array}$ & $\begin{array}{l}12,3 \% \\
69,7 \%\left(^{*}\right) \\
5,7 \% \\
12,3 \%\end{array}$ \\
\hline Avaliação & $\begin{array}{l}\text { Análise das respostas de testes } \\
\text { Analise do material produzido } \\
\text { Participação na ação } \\
\text { Relatório } \\
\text { Sem referência }\end{array}$ & $\begin{array}{l}40,2 \%\left({ }^{*}\right) \\
2,9 \% \\
29,4 \%\left({ }^{*}\right) \\
1 \% \\
26,5 \%\end{array}$ & $\begin{array}{l}44,4 \%\left({ }^{*}\right) \\
- \\
23,3 \% \\
- \\
32,2 \%\left({ }^{*}\right)\end{array}$ & $\begin{array}{l}42,2 \%\left(^{*}\right) \\
1,6 \% \\
26,6 \%\left(^{*}\right) \\
0,5 \% \\
29,2 \%\left(^{*}\right)\end{array}$ \\
\hline Conclusão & $\begin{array}{l}\text { Houve conscientização } \\
\text { Houve informação } \\
\text { Informação deficiente } \\
\text { Sem } \\
\text { Tem Informação, mas não Pratica }\end{array}$ & $\begin{array}{l}24,4 \% \\
21,8 \% \\
10,3 \% \\
39,7 \%\left(^{*}\right) \\
3,8 \%\end{array}$ & $\begin{array}{l}11,1 \% \\
11,1 \% \\
- \\
55,6 \%\left(^{\star}\right) \\
22,2 \%\end{array}$ & $\begin{array}{l}17,3 \% \\
16,1 \% \\
4,8 \% \\
48,2 \%\left(^{*}\right) \\
13,7 \%\end{array}$ \\
\hline
\end{tabular}

A homogeneidade das frequências absolutas das categorias relativas a cada parâmetro avaliado foi comparada por meio do teste de aderência Goodness of Fit (GTest), sendo os valores significativamente maiores acompanhados de asterisco $\left(^{*}\right)$.

Fonte: Dados da pesquisa. 
Para metodologias utilizadas nos conteúdos analisados, as mais frequentes foram: "contato direto com objeto de estudo" (27,3\%), questionário $(26,2 \%)$, palestra $(10,9 \%)$ e teatro $(10,6 \%)$ (Figura 1$)$.

$\begin{array}{lll}\text { - Contato direto prática } & \mathbb{Q} \text { Questionário } & \square \text { Palestras } \\ \square \text { Teatro } & \mathbf{Q} \text { Informacao } & \text { Dinamica de grupo } \\ \square \text { Video } & \square \text { Produção artistica } & \square \text { Elaboração de material didático }\end{array}$

$\square$ Revisão bibliográfica

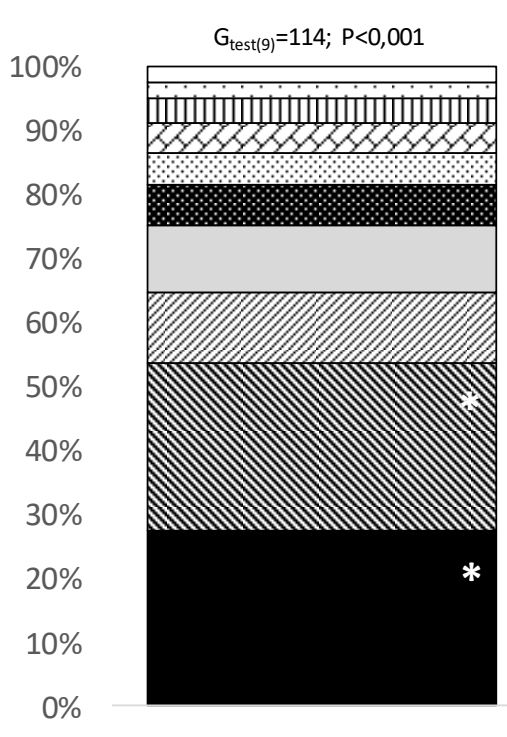

Total $(\mathrm{N}=282)$

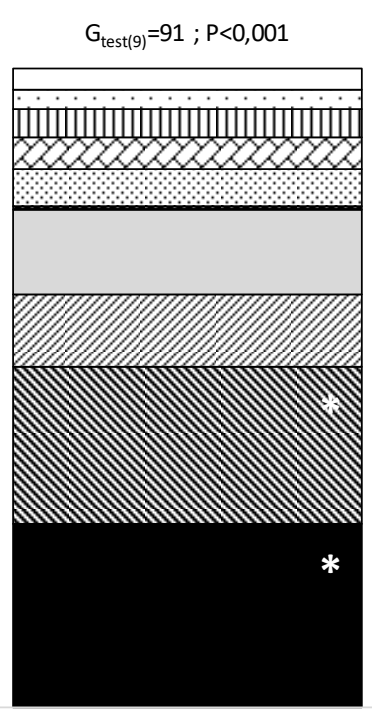

Científico $(\mathrm{N}=204)$
$G_{\text {test(9) }}=24 ; P<0,001$

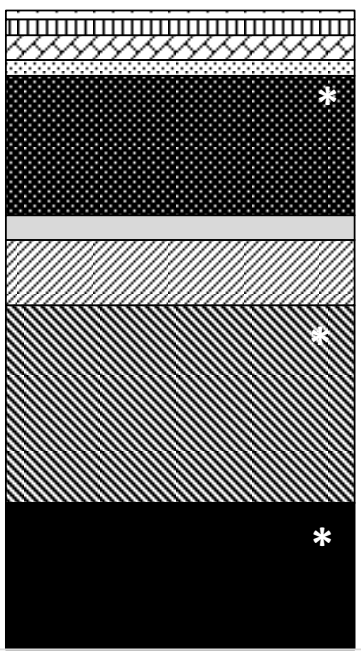

Popular ( $\mathrm{N}=78)$

Figura 1: Frequência relativa dos métodos nos conteúdos analisados no total dos textos sobre Educação Ambiental e no meio científico e popular.

A homogeneidade das frequências absolutas das categorias relativas a cada parâmetro avaliado foi comparada por meio do teste de aderência Goodness of Fit (G $\mathrm{G}_{\text {Test }}$ ), sendo os valores significativamente maiores acompanhados de asterisco $\left(^{*}\right)$.

Fonte: Dados da pesquisa. 
artigos, foram citados apenas três autores: Augusto Boal, Viola Spolin e Sociopoética de Jacques Gauthier (Figura 2).

Dos artigos científicos que usaram o teatro como ferramenta, metade indicou os métodos de avaliação, destacando-se a escrita e o debate, enquanto que o mesmo montante apresentou os resultados da intervenção, sendo relatada com maior frequência a participação dos educandos (Figura 2).

Em relação ao público, $75 \%$ dos textos focaram nas crianças e dois apresentaram dois públicos. Em $50 \%$ dos relatos houve a participação direta dos educandos nas práticas de teatro, e destes só dois apresentaram participação dos educandos na prática de teatro, e também outra fase como expectadores. Um dos trabalhos analisados discutiu a importância de participar, na prática, de teatro e de somente assistir.

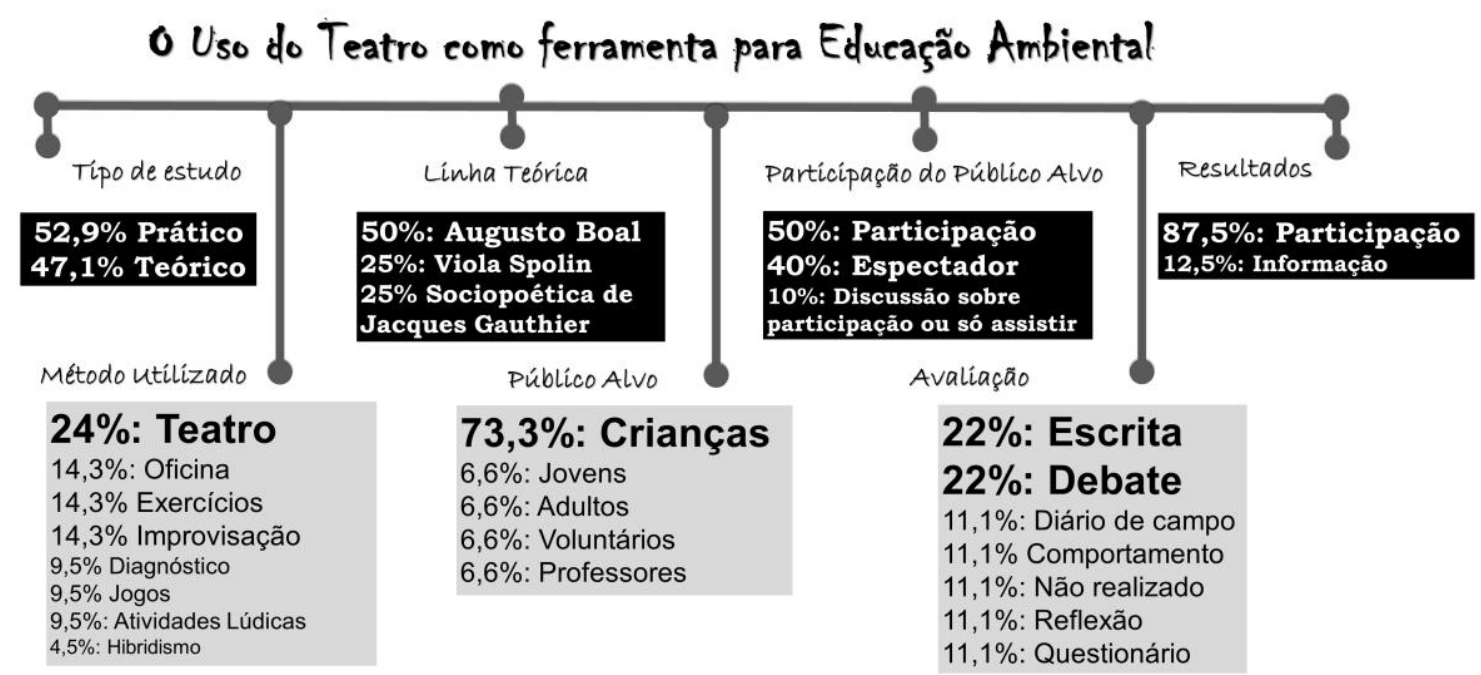

Figura2: Fluxograma da categorização dos textos científicos que utilizaram o teatro como ferramenta para a intervenções de Educação Ambiental.

Fonte: Dados da pesquisa.

\section{Entrevistas com Educadores Ambientais}

Os biólogos entrevistados que atuavam na EA desenvolveram trabalhos para públicos e com temas diversificados. As intervenções de EA foram direcionadas para a comunidade, as crianças, os professores e os adultos, tendo como temas: a capacitação de monitores, os resíduos sólidos, a erradicação da dengue e as visitas orientadas ao zoológico. Para quatro entrevistados, a maior expectativa de satisfação era concluir a intervenção e lograr a almejada mudança de comportamento; para dois deles, era reconhecer o interesse das pessoas com o tema desenvolvido; e para os dois últimos a satisfação era pautada na possibilidade de transmitir conhecimentos para os professores, devido a seu papel educação das futuras gerações e se cientificar de que ainda existem pessoas preocupadas com a natureza, destacando a preservação da araucária. Igualmente quatro entrevistados responderam que a 
falta de continuidade dos projetos é a maior dificuldade para quem se propõe a realizar uma intervenção em EA. Para outros quatro, a dificuldade está atrelada à falta de investimento. Enquanto os dois entrevistados restantes apontaram limitações na conscientização, a falta de interesse, comprometimento e o distanciamento da população da natureza. Todos os entrevistados concordaram que para atingir públicos diferentes deve-se conhecer o contexto histórico, a faixa etária, o nível de conhecimento e a linguagem diferenciada de acordo com o público.

Os entrevistados citaram diferentes ferramentas para a aplicação da EA, tais como: contato direto (20\%), palestras (40\%), exposições $(10 \%)$, vídeos (10\%), diálogo com os participantes (20\%) e metodologias colaborativas (10\%). Para metade dos entrevistados o teatro e as atividades lúdicas são as melhores ferramentas, acrescidas das vivências dos participantes $(10 \%)$, afirmando que o contato direto com a natureza é mais efetivo na conscientização. Já para dois entrevistados, as atividades mais participativas são as mais eficientes, enquanto para um deles, o melhor é a utilização de modelos que trabalham as lideranças em que se ensina a comunidade a participar ativamente das tomadas de decisões.

Todos os entrevistados utilizaram o teatro como ferramenta para promoção da $E A$, sendo citados o teatro de fantoches, o teatro vivo, a contratação de um ator e a dança. Houve unanimidade na atribuição da efetividade do teatro para a $E A$, relacionada ao fato de as atividades serem realizadas descontraidamente por informar os participantes por meio do lúdico, e por ser uma ferramenta de sensibilização que instiga a conhecer mais os assuntos. Contudo, um entrevistado afirmou que mesmo sendo o teatro uma excelente ferramenta, não é possível alcançar um resultado satisfatório aplicando apenas uma ferramenta.

Como avaliação dos resultados, dois entrevistados afirmaram que utilizavam o feedback; dois por meio de uma linha telefônica disponibilizada para os participantes do projeto, em que podiam fazer reclamações ou sugestões, um pela demanda do público; um por meio de pré-teste e pós-teste. Para quatro entrevistados a avaliação deve ser aplicada novamente depois de alguns meses ou um ano do termino do projeto, a fim de medir a incorporação do conteúdo trabalhado.

\section{Profissionais do teatro}

A maioria dos atores entrevistados disse já ter trabalhado com o teatro em ações educativas; dois deles relataram trabalhar de forma educativa em qualquer peça encenada, enquanto outros dois utilizaram o teatro em ações educativas de forma lúdica e não didática. $O$ teatro foi utilizado em sala de aula com a temática ambiental, em peças convencionais e em sala de aula, mas com a finalidade de ensinar interpretação de texto. Dois entrevistados disseram ter participado de espetáculos para jovens com a temática educação sexual e espetáculos infantis com temas variados. Outros entrevistados participaram de 
teatro na empresa, no qual instruía os funcionários em atividades envolvendo temas da cultura greco-romana e outra peça na qual se arrecadava ração para animais abandonados.

Todos os entrevistados, responderam que o teatro é eficiente em ações educativas, mesmo os dois deles nunca tenham vivenciado ações educativas com o teatro. Sete entrevistados relacionaram a eficiência na capacidade de instigar o público à reflexão e à busca de conhecimentos. Destes, três disseram que o teatro é eficiente por aproximar as pessoas da realidade e um dos entrevistados utilizou a frase "o teatro é o ensaio da vida real", citando Boal. Outros dois responderam que por meio de um objetivo claro, textos bem elaborados e atores bem preparados, é possível potencializar a eficiência da ferramenta teatro em ações educativas e um deles relacionou com apelo visual e sonoro transmitindo informações de uma forma descontraída.

Quanto aos pré-requisitos para a aplicação do teatro como ferramenta educativa, embora todos os entrevistados tenham afirmado que estudar técnicas de teatro seria o mais interessante, dois deles responderam que é possível recorrer aos profissionais de teatro e um afirmou que é fundamental ter bons textos e saber como passar as informações para o público. Dois atores relacionaram o sucesso da ferramenta com vontade e dedicação. Todos os entrevistados responderam que se deve diferenciar a forma de teatro em relação à idade e classe social, bem como à linguagem utilizada de acordo com o público. Um entrevistado frisou que, além desses critérios, deve-se conhecer o público, principalmente seu contexto histórico, e para três entrevistados, o gosto do público deve ser levado em consideração.

Para sete atores, a forma mais eficaz de aprender é quando o educando tem a oportunidade de atuar, devido ao tempo de estudo e aprofundamento no tema, porém um entrevistado alertou que dependente da disponibilidade, da aptidão e da vontade das pessoas envolvidas. Dois entrevistados responderam que é possível aprender atuando e como espectador; seis autores opinaram que a forma ideal de avaliação é por meio do contato com o público depois da encenação, dois deles ressaltaram que o trabalho do ator é comunicar e que se a mensagem for passada o trabalho do ator foi cumprido.

\section{Discussão}

Os dados do presente estudo evidenciaram sob diferentes recortes e perspectivas que o teatro é uma ferramenta importante nas ações da EA, demandado a consonância de objetivos, métodos e público alvo, o qual deve ser diagnosticado para a utilização apropriada da linguagem.

Os textos científicos com abordagem de EA analisados nesta pesquisa indicaram a existência de um direcionamento para a investigação de novas metodologias, sugerindo uma relação com a fase de desenvolvimento da EA no Brasil, em que ainda se procura melhores formas de construir cidadãos conscientes (ARAUJO; AMORIM, 2014, VIDAYPATI; SAHAE, 2014, SAGY; TAL, 2013, LOUREIRO, 2009, LAYRARGUES, 2004, SATO, 2003). Contudo, a

revista brasileira educação ambiental 
concretização dessa expectativa requer inicialmente diagnosticar o público trabalhado, permitindo assim conhecer suas realidades, objetivos e desejos (FISCHER et al. 2017c, ARAUJO; AMORIM, 2014, SOUSA, 2011, ARAÚJO; PASQUARELLI, 2006). Dessa forma devem-se estruturar atividades com linguagens, conteúdos e formas próximas da realidade do grupo, acessado por meio de suas vivências (ARAUJO; AMORIM, 2014, SOUSA, 2011, ICLE, 2001), a fim de que concebam, baseados em valores coletivos, novas condutas e estilos de vida que impactem o menos possível na saúde do planeta. Por essas razões a população deve receber informação que balize uma sensibilização, e por fim, sconcretize-se a conscientização, concluindo as três etapas da EA (GUIMARÃES, 2007). Todos esses fatores, quando trabalhados de forma incipiente, dificultam as práticas de educação, e obviamente, prejudicam os resultados. Fischer e Furlan (2017) e Fischer et al. (2017c) sugeriram o planejamento de intervenções de EA associadas com a Bioética Ambiental a partir das evidências das representações que cada grupo faz dos elementos da natureza, sendo a inserção da aprendizagem nas questões éticas cotidianas detentor de potencial para tornar os conteúdos mais relevantes ao educando.

A educação formal caminha lentamente para uma educação integrada e contextualizada, inserindo a EA na escola, focando nas experiências individuais e coletivas de cada educando pautados nas suas realidades (CRUZ; SILVA; ANDRADE, 2016; CRUZ; SILVA; ANDRADE, 2016; CALSADO, 2015; FRANÇA; SOUZA NETO; 2015; MENG; LI, 2014; VIDAYPATI; SAHAE, 2014; CARVALHO; DIAS, 2013; SILVA; COSTA; ALMEIDA, 2012; THE CLUTE ISTITUTE, 2011; LAYRARGUES, 2004; REIGOTA, 1998; CARVALHO, 1992; FREIRE, 1976). Os resultados do presente estudo corroboram com esses conceitos, uma vez que as análises dos textos científicos apresentaram diversidade de temas nas intervenções da EA destacando-se recursos hídricos, lixo, sustentabilidade e poluição, sugerindo que os trabalhos estão pautados nos problemas reais, integrando as realidades e promovendo condições para que a população tome iniciativas e decisões benéficas para coletividade (LAYRARGUES, 2004; SATO, 2003). Os temas devem ser trabalhados para a preservação e conservação do planeta, permitindo que a população atual e futuras gerações possam viver dignamente. Portanto, as ações em EA buscam novas formas de abordar a população, focar nos problemas reais de cada indivíduo, para que assim, instigue a participação de todos nas tomadas de decisões socioambientais.

O fato das ações de EA focar no público infantil é embasa na importância desta fase de desenvolvimento na formação da personalidade e valores, facilitando a mudança de comportamento e atitudes (FISCHER et al., 2016). A utilização de atividades lúdicas nas ações de EA é justificada por ser um método descontraído e que desenvolve o intelecto, tendo bons resultados com esse público, corroborando com a maioria dos biólogos entrevistados no presente estudo e com Guerra et al. (2004), Palhano (2001), Piaget (1997). Ao escolher o público da ação deve-se levar em consideração a adequação da metodologia adotada, para tal deve-se inicialmente: diagnosticar os educandos Revbea, São Paulo, V. 12, № 5: 56-72, 2017. 
quanto ao contexto histórico, faixa etária e assim, utilizar a linguagem que melhor se adéque ao público (ARAUJO; AMORIM, 2014; SOUSA, 2011; FISCHER, et al. 2006). Para Guimarães (2007), Sato (2003) e também os biólogos entrevistados, as metodologias que envolvem o contato direto com a natureza e a intensidade com que essa prática acontece, atinge os sentidos e sentimentos dos participantes, permitindo assim conscientizar os mesmos. Outro ponto citado por Cruz, Silva e Andrade (2016), Silva et al. (2016), Silva, Costa e Almeida (2014), Meng e Li (2014), Carvalho e Dias (2013), Hsieh (2013), Sagy e Tal (2013) The Clute Institute (2011), Sato (2003) e um dos entrevistados foi o de trabalhar na formação dos educadores, afinal são esses profissionais que educaram as futuras gerações. Seja qual for o público devemse utilizar as ferramentas certas e estrutura-las de acordo com os educandos para que a prática da Educação Ambiental atinja seus objetivos.

O levantamento dos trabalhos que abordaram a EA indicou que a maioria encontra dificuldade em avaliar e concluir os resultados, devido ao fato de não conseguirem avaliar com precisão se ocorreu ou não a conscientização. A mensuração da intensidade em que informações trabalhadas tocaram os participantes é complexa, portanto, mesmo depois da prática em EA, avaliar se o indivíduo mudará seu comportamento (CALSADO et al., 2015; FISCHER et al. 2006; ARAÚJO; PASQUARELLI, 2006). Segundo a maioria dos entrevistados, outro fator limitante na avaliação e conclusão das práticas em EA é a falta de investimento, pois os recursos são reduzidos, fazendo com que o tempo de trabalho diminua e consequentemente, não haja continuidade das atividades, prejudicando alcançar os resultados esperados, os quais se tornam superficiais (FRANÇA; SOUSA NETO, 2015; FISCHER et al. 2006). Fischer et al. (2016) propuseram o uso da teoria do desenvolvimento moral de Kholberg como ferramenta para atestar o desenvolvimento moral dos estudantes na aplicação da Bioética no contexto educacional. Segundo os autores, a associação entre o desenvolvimento biológico e psicossocial favorece a orientação da aplicação de ações direcionadas ao desenvolvimento cognitivo, emocional e moral, sendo possível mensurá-las por testes, muitas delas já validadas.

Os artigos científicos que utilizavam o teatro como ferramenta em ações da EA, no recorte proposto pelo presente estudo, permitiram avaliar que o teatro é importante para a conscientização e compreensão da vida, construindo seres humanos mais completos. Não apenas no sentindo de oferecer à sociedade humanos prontos, mas sim, seres flexíveis e diferentes. Com isso, torna-se uma excelente ferramenta em ações educativas, seja de cunho ambiental ou não (ARAUJO; AMORIM, 2014; SOUSA, 2011; BARCELOS, 1975). Segundo a presente investigação, essa prática vem sendo mais utilizada, acrescida da música, cinema e atividades que envolvam cultura (FRANÇA; SOUSA NETO, 2015; ARAUJO; AMORIM, 2014; VIDAYPATI E SAHAE, 2014; SOUSA, 2011).

O teatro instiga a reflexão e para que haja o aprofundamento cognitivo almejado se deve dotar o educando de informação e conhecimento. Por isso 
muitas vezes as práticas de teatro em ações de EA não são bem estruturadas, pois são consideradas maneiras descontraídas de informar, principalmente pelos biólogos. Segundo os atores entrevistados, o teatro deve ser utilizado como uma ferramenta reflexiva, devendo estudar os fundamentos do teatro ou até mesmo unir educadores ambientais, com o conteúdo a ser trabalhado, e o ator, conhecedor das técnicas do teatro de forma a atingir o público. Dessa forma, potencializar os meios dos cidadãos refletirem sobre as realidades e os problemas socioambientais. Muitos autores teatrais criaram seus trabalhos pautados nos problemas humanos como Augusto Boal (1998), Viola Spolin (1979), Bertolt Brecht (1967), e atualmente, alguns educadores, aperfeiçoam essas técnicas para atingir resultados satisfatórios nas causas ambientais que não deixam de ser problemas sociais. Para Boal (1998), o teatro é um ensaio da realidade, faz com que as pessoas observem suas relações de outro ângulo e assim, com autonomia e clareza, construa novas perspectivas (SITTA; POTRICH, 2005; BRASIL, 1998). Ainda segundo Boal (1998) O teatro pode ser concebido como uma arma de certas classes sociais, as quais permanentemente tentam apropriar-se do mesmo e utilizá-lo como instrumento de dominação, descaracterizando o inerente conceito do teatro. Porém, Boal (1998) conclui que o teatro pode ser igualmente uma arma de libertação, demandando de formas teatrais correspondentes e transformação. Logo, o teatro deve ser integrado na educação de forma séria e objetiva, não através de uma atividade descontraída ou um passatempo, pois essa ferramenta possui um excelente potencial na educação, já que permite sensibilizar públicos diversos, através da aproximação da realidade. Fischer et al. (2016) ao analisarem a aplicação da teoria do desenvolvimento moral nas questões ambientais por diferentes autores, elucidaram que a vivência na situaçãoproblema é um efetivo meio de promoção de mudanças de níveis de moralidade. Esse processo é potencializado quando estudantes de diferentes níveis são inseridos no contexto pretendido e oferecido a oportunidade de argumentarem seus julgamentos morais. Assim, eleva-se o nível moral do educando, por meio da oportunidade de presenciar a argumentação do colega detentor de um nível mais elevado. Neste contexto, o uso do teatro como meio de simular situações-problemas detentoras de questões bioéticas, se constitui de uma ferramenta que alia a educação moral para questões socioambientais.

No levantamento realizado em relação à avaliação das práticas de EA que utilizaram o teatro como ferramenta, também se percebeu a falta de investimento e a descontinuidade das ações. Contudo, as avaliações mais frequentes foram por meio de debates e questionários. Para os atores entrevistados o artista, que não utiliza o teatro como ferramenta propriamente dita para ações educativas, o único contato com o público é através da sintonia durante o espetáculo, dificultando assim, a avaliação e o impacto com que a mensagem chegou aos espectadores. Como qualquer ferramenta utilizada para ações educativas, os resultados são a médio e longo prazo. $O$ teatro permite bons resultados que se percebe momentaneamente na expressão dos espectadores, mas as transformações efetivas serão percebidas através de novas atitudes e comportamentos (ARAÚJO; PASQUARELLI, 2006). 
Entretanto o teatro sozinho não é hábil na construção de cidadãos conscientes, devendo se unir à educação, que é de responsabilidade da família e da sociedade (MENG; LI, 2014; VIDYAPATI; SAHAE, 2014; THE CLUTE INSTITUTE, 2011; BRASIL, 1997). Um dos entrevistados disse que o ator é um formador de opinião e por meio da arte, deve comunicar sua mensagem, não simplesmente uma comunicação do indivíduo, mas como reflexão de uma sociedade (BARCELOS, 1975), atingindo a essência de quem assiste e permitindo, assim, que o teatro contribua na formação de sujeitos autônomos, críticos e protagonistas (SITTA; POTRICH, 2005). Por todas essas características o teatro acompanha a humanidade desde seus primórdios, instigando reflexões e atitudes para a construção de um mundo mais ético, digno e natural para todos os seres vivos.

\section{Conclusão}

Os resultados do presente estudo atestaram que o teatro é uma ferramenta relevante para a $E A$, porém poderia ser mais utilizada. $O$ teatro instiga a reflexão e permite que os indivíduos observem o mundo em múltiplos ângulos, levantando questionamentos e, assim, transformando-se em cidadãos autônomos, conscientes, críticos e protagonistas nas tomadas de decisões pautadas em valores coletivos em prol do bem-comum. Contudo, a eficiência da ferramenta demanda planejamento estruturado, que considere as realidades do público alvo e utilize linguagens que facilitem a compreensão da mensagem. Para tal, faz se necessário a união de educadores ambientais e atores, para que o objetivo seja alcançado com êxito. Logo, deve-se inserir na educação formal e não formal e em todos os níveis de ensino. Contudo, não apenas como uma simples matéria ou mesmo como uma forma de descontração, mas visando a integração com todas as disciplinas voltadas para as problemáticas reais. Os dados do presente estudo corroboram para a sugestão de Fischer e Furlan (2017) quanto à implementação de comitês de bioética ambiental nas escolas. Segundo os autores comitês multidisciplinares formados por educadores, educandos e representantes de diferentes setores da sociedade que se interessam pela qualidade da educação, acrescido de um bioeticista, poderiam ter como função intermediar o diálogo diante de questões bioéticas de interesse socioambiental locais com repercussões globais. Diante dessas questões o comitê é hábil para refletir, orientar, deliberar e propor intervenções que visem ao aprimoramento dos educadores a fim de respaldar a construção do almejado cidadão comunitário que preza pela qualidade de todas as formas de vida, desta e de outras gerações.

\section{Agradecimentos}

Aos biólogos e atores entrevistados cuja colaboração foi fundamental para a realização desta pesquisa. 


\section{Referências}

ARAUJO, M.F.F.; AMORIM, A.S. Percepção de professores sobre o uso de atividades lúdicas para tratar o tema "água e saúde" em ações de Educação Ambiental numa região semiárida. Revista Holos, ano 20, v. 6, 2014.

ARAÚJO, A.F.; PASQUARELLI, J.R.V. Educação Ambiental e teatro: um caminho de pesquisa e ação. Anais do II fórum ambiental da Alta Paulista. 2006. Disponível em: <http://www.amigosdanatureza.org.br/noticias/ 306/trabalhos/155.EA-21.pdf> acessado em 2 outubro>. Acesso em: 2010.

ARAUJO, A.F.; PASQUARELLI, V.J. Teatro e Educação Ambiental: um estudo sobre ambiente, expressão estética e emancipação. Revista Eletrônica do Mestrado em Educação Ambiental (Remea), v. 18, 2013.

BARCELOS, H. Desenvolvimento da linguagem teatral da criança. Revista de Teatro do Seminário de Teatro Infantil (Sbat). Serviço Nacional de Teatro. Rio de Janeiro: MEC, 1975. p. 30-34.

BARDIN, L. Análise de conteúdo. Lisboa: Edições 70, 2011.

BERTHOLD, M. História mundial do teatro. Rio de Janeiro: Perspectiva, 2005. 578 p. ISBN 85-273-0228-4.

BOAL, A. Jogos para atores e não atores. 14. ed. rev. e ampl. Rio de Janeiro: Civilização Brasileira, 1998. 247 p. ISBN 85-200-0118-1.

BOAL, A. 200 exercícios e jogos para o ator e o não ator com vontade de dizer algo através do teatro. Rio de Janeiro: Civilização Brasileira, 1977. 123 p. v. 3. (Coleção Teatro Hoje).

BRASIL. Ministério da Educação e do Desporto. PCN: Arte (Educação Fundamental - primeira à quarta série). Brasília, 1997.

BRASIL. Ministério da Educação e do Desporto. PCN: Arte (Educação Fundamental - quinta à oitava série). Brasília, 1998.

BRECHT, B. Bertolt Brecht. Rio de Janeiro: Civilização Brasileira, 1967. CALSADO, C.F.; YANGCO, R.T.; MUEGA, M.B.C. Implication of students' cognitive style, personal demographics, values and decision marking in Envirenmental Education. International Journal of Art \& Sciences, 2015.

CARVALHO, I.C.M. Educação, meio ambiente e cidadania. In: CONGRESSO SOBRE ESSÊNCIAS NATIVAS, 2, 1992, São Paulo. Anais... São Paulo: Instituto Florestal, 1992. p. 1081-1085.

CARVALHO, R.V; DIAS, R. O Desenvolvimento de uma cultura ambiental corporativa através da E.A. Revista em Agronegócios e Meio Ambiente, v. 6, n. 3, p. 479-496, set./dez. 2013.

CRUZ, F.C.F.; SILVA, M.F.S.; ANDRADE, S.I.M. Percepção socioambiental dos alunos de Ensino Fundamental de uma escola municipal de Caxingó, Piauí, Brasil. Revista Holos, ano 32, v. 4, 2016.

FISCHER, M.L.; FURLAN, A.L.D. Bioética e Educação: Concepção da terminologia bem-estar-animal por estudantes do Ensino Básico. Revista 
Brasileira de Pesquisa em Educação em Ciências, v. 17, n. 2, p. 399-422, 2017.

FISCHER, M.L.; MOLINARI, R.B. Bioética ambiental: a retomada do cunho ecológico da bioética. In: SGANZERLA, A. SCHRAMM FR. Fundamentos da Bioética série Bioética vol. 3. Curitiba: CRV, 2016, p. 233-253.

FISCHER, M.L.; MOSER, A.M.; FURLAN, A.L.D. Bioética e Educação: a utilização do nivelamento moral como balizador para construção de um agente moral consciente, autônomo e reflexivo. In: RENK, V. E. Bioética e Educação: múltiplos olhares. Curitiba: Prisma, 2016. p. 33-67.

FISCHER, D.; TORRES, R.F.; URBAN, T. Um rio perto daqui. Curitiba: Mater Natura - Instituto de Ambientais, 2006.

FISCHER, M.L. et al. Da Ética Ambiental à Bioética Ambiental: antecedentes, trajetórias e perspectivas. Revista História, Ciência, Saúde-Manguinhos, v. 24, n. 2, p. 391-409, 2017a.

FISCHER, M.L. et al. Caminho do diálogo: uma experiência bioética no Ensino Fundamntal. Revista Bioética, v. 25, n. 1, 2017b.

FISCHER, M.L. et al. Bioética Ambiental e Educação Ambiental: levantando a reflexão a partir da percepção. Revista Brasileira de Educação Ambiental (RevBEA), v. 12, n. 1, p. 58-84, 2017c.

FRANK, G. The Medieval Ferati drama. Rio de Janeiro: Perspectiva, 1954. 578 p. ISBN 80-273-0328-8.

FRANÇA, J.P.; SOUZA NETO, L.T.O Calendário Ecológico escolar: uma experiência de EA no Ensino Fundamental. Revista Holos, ano 31, v. 6, 2015.

FREIRE, P. Pedagogia do oprimido. Petrópolis: Vozes, 1976.

GUERRA, R.A.T.; GUSMÃO, C.R.C.; SIBRÃO, E. R. Teatro de fantoches: uma estratégia em Educação Ambiental. João Pessoa: Universidade Federal da Paraíba, 2004.

GUIMARÃES, M. A formação de educadores ambientais. 4. ed. Campinas:

Papirus, 2007. $174 \mathrm{p}$.

HSIEH, H.R. Case study on the Environmental Education application status for water recycling facilities in Elementar and Junior high schools in Yilan. Applied Mechanics and Materials, v. 284-287, p. 1453-1457, 2013.

ICLE, G. Teatro escola: aproximações e distanciamentos. Pátio - Revista Pedagógica, Porto Alegre, v. 5, n. 17, p. 58-61, maio/jul. 2001.

LAYRARGUES, P.P. Determinismo biológico: o desafio da alfabetização ecológica na concepção de Fritjof de Capra. Disponível em: $<$ http://www.hortaviva.com.br>. Acesso em: 3 out. 2010.

LEFF, H. Educação Ambiental e desenvolvimento sustentável. In: REIGOTA, M. (Org.). Verde cotidiano: o meio ambiente em discussão. Rio de Janeiro, DP\&A, 1999. p. 111-129.

LOUREIRO, C.F.B. Trajetória e fundamentos da Educação Ambiental. São Paulo: Cortez, 2009. 150 p.

revista brasileira educação ambiental 
MULLER, V.L.S; FARIA, M. E. Educação Ambiental e formação de professores: reflexão sobre a coleta seletiva de lixo. Anais do V ENCONTRO NACIONAL DE PESQUISA EM EDUCAÇÃO EM CIÊNCIA. Bauru, 2005.

MENG, X.; LI, S. Study on the Environmental Education of hydraulic engineering. Applied Mechanics and Materials, v. 672-674, p. 2249-2249, 2014. ISSN: 1662-7482.

PALHANO, R.R. Teatro de bonecos: uma alternativa para o Ensino Fundamental na Amazônia. Fundação Universidade Federal do Amapá, Macapá, 2001.

PIAGET, J. Seis estudos de Psicologia. Rio de Janeiro: Rorense, 1997.

REIGOTA, M. Meio Ambiente e representação social. São Paulo: Cortez 1998.

SAGY, G.; TAL, A. Greening the curriculum: current trends in Environmental Education in Israel's Public Schools. Israel Studies, v. 20, n. 1, 2015.

SANTOS, J.E.; SATO, M. A contribuição da Educação Ambiental à esperança de Pandora. São Carlos: Rima, 2003.

SATEDSP, 2010. Disponível em: <http://www.satedsp.org.br/departamentojuridico.html>.

SATO, M. Educação Ambiental. São Carlos: Santos, J. E. Rima, 2003. ISBN: 85-86552-27-2.

SILVA, E. et al. Validação e aplicação de uma escala de medida sobre práticas ambientais em escolas do Ensino Médio da cidade de Patos, Paraíba. Acta Scientiarum. Biological Sciences. Maringá, v. 38, p. 319-325, jul./set. 2016.

SILVA, L.O.; COSTA, A. P. L.; ALMEIDA, E. A. Educação Ambiental: o despertar de uma proposta crítica para a formação do sujeito ecológico. Revista Holos, ano 28, v. 1, 2012.

SITTA, M.; POTRICH, C. Teatro: espaço de educação, tempo para a sensibilização. Passo Fundo: UPF, 2005.

SOUSA, A.C.B. Educação Ambiental e o teatro na história: uma experiência em Balbino, Ceará. Universidade Federal do Ceará. Prodema - Programa Regional de Pós-Graduação em Desenvolvimento e Meio Ambiente, 2011.

SPOLIN, V. Improvisação para o teatro. São Paulo: Perspectiva, 1979.

TELLES, M.Q. Vivências integradas com o meio ambiente. São Paulo: Sá, 2002. p. 42.

THE CLUTE INSTITUTE. ELT teacher trainess' attitudes towards Environmental Education and their tendency to use it in the language classroom. Journal of International Education Research - Fourth Quarter v. 7, n. 4, 2011.

THIOLLENT, M. Metodologia da pesquisa-ação. 8. ed. São Paulo, 1988.

VIDYAPATI; SAHAE, J.P. Curricular and Co-Curricular dimensions of Environmental Education. Na Int. J. of Educational Technology, v. 4, n. 2, p. 55-59, dec. 2014.

Revbea, São Paulo, V. 12, № 5: 56-72, 2017. 